\title{
The Digital Media in Lithuania: Combating Disinformation and Fake News
}

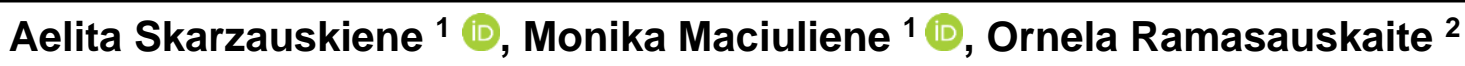

\begin{abstract}
The prevalence of so-called "fake news" is a relatively recent social phenomenon that is linked to disinformation, misinformation and other forms of networked manipulation facilitated by the rise of the Internet and online social media. The spread of misinformation is among the most pressing challenges of our time. Sources from which disinformation originates are constantly changing and present an enormous challenge for real-time detection algorithms and more targeted science based socio-technical interventions. The primary aim of this paper is to illuminate the practices and interpretations, focusing on three perspectives: general attitudes to fake news, perceived interaction with disinformation and opinion on counteraction with respect to fake news. The innovative character of the research is achieved by the focus on community solutions to combat disinformation and the collaboration between media users, media organizations, scientists, communication managers, journalists and other important actors in the media ecosystem. Based on insights from interviews with communication field experts, the paper sheds light on the efforts of Lithuanian society to confront the problem of fake news in digital media environment. Lithuania is also an interesting case study for fake news due to its status as a former Soviet state now in the EU. Our research indicates that not all media users are prepared and/or have the necessary competencies to combat fake news, so that citizen engagement might actually negatively influence the quality of the counteraction process. Indeed, proactive citizens' organizations and NGOs could be an important catalyst fostering collaboration between stakeholders. The responsibility of governments could be to create the structures, methodologies and supporting educational activities to involve the stakeholders in collaborating activities combating disinformation.
\end{abstract}

Keywords: Fake news; Disinformation; Collaboration; Digitalization, Media.

\section{Introduction}

The ever-expanding role of the Internet in disinformation and manipulation in online environments is being explored by many researchers and communication professionals. In times of crisis, social media helps distribute knowledge, but this is accompanied by the spread of disinformation through social media bots and cyborg accounts. Fake news in the form of disinformation benefits from the speed of information dissemination in today`s media ecosystem. The term "fake news" was named the Collins Word of the Year 2017 due to the

\footnotetext{
${ }^{1}$ Faculty of Creative Industries, Vilnius Gediminas Technical University,

Sauletekio Al. 11, Vilnius, Lithuania

$\square$ aelita.skarzauskiene@vgtu.lt

${ }^{2}$ Faculty of Social Sciences, Arts and Humanities, Kaunas University of Technology,

K. Donelaičio St. 73, Kaunas, Lithuania
} 
unprecedented increase in its usage, or $365 \%$ in the Collins Corpus (Reuter et al., 2019). Following the 2016 US presidential elections, interest in the term "fake news" increased dramatically, as indicated by its prominence on news channels, and also Google Search queries for this expression (Cunha et al., 2018). Negativity surrounding news containing the term "fake news" increased during the recent Covid-19 pandemic (Garrett, 2020), which has been described as the first major "infodemic" of the social media age, according World Health Organisation (Jourova, 2020).

All of these developments increase the public interest in Fake news and result in changes of its conceptualization and perception. As the sources of disinformation are in a constant state of flux, the challenge now is to develop real-time detection algorithms and targeted science based socio-technical interventions. In facing down the threat of fake news, the biggest social media platforms, search engines (primarily Google and Wikipedia), and also the most important news agencies (BBC, as well as DW, Agence France-Presse and ANSA) look for innovative technological solutions which could help to eliminate fake news in the early stages. These companies offer many different toolboxes, such as Fast cCeck, InVid, Verification Plugin, FotoForensics, to assist media organisations and journalists to verify news (Combating Fake News, 2017). One example of a technological intervention that can limit the spread of false information by delivering warnings before people share disputed articles is Facebook's initiative of partnering with fact-checking organizations like Snopes, Politifact and the Associated Press. Recently, Google, Reddit, LinkedIn, Microsoft, Twitter and YouTube committed to removing coronavirus-related disinformation from their platforms.

Another important problem in the context of technological advancement resides in the social factors that are able to counteract disinformation - community solutions, media literacy, awareness of threats and the preparedness of citizens to be engaged in fighting fake news. "Historically, the biggest challenge for communities experiencing a crisis event was often a lack of information, especially information from official sources. ... In the connected era, the problem isn't a lack of information but an overabundance of information and the challenge of figuring out which information we should trust and which information we shouldn't trust" (Starbird, 2020).

The present study combines the following streams of scholarship in the theoretical part of the paper: firstly, the study of fake news and the problems in their identification and dissemination (Section 2), secondly, the issues of media reception; and thirdly, fostering the culture of truth through community solutions (Section 3). Sections 4 and 5 present a methodology of qualitative research and insights form expert interviews in Lithuania from three analytical perspectives: attitudes towards fake news, interaction experience and possibilities for counteracting disinformation with special focus on collaboration between stakeholders. Discussion and conclusions are outlined in Section 6.

\section{Research on Fake news and their threats}

Fake news is a social phenomenon linked to disinformation, misinformation and other forms of networked manipulation, which in recent years has been facilitated by the rise of the Internet and online social media. The term "fake news", defined as "false, often sensational, information disseminated under the guise of news reporting" (Reuter et al., 2019) has gained much attention. For example, "from 2003 to 2017 the term 'fake news' has been used to refer to things as varied as news satire, parody, fabrication, manipulation, advertising, and propaganda" (Tandoc, 2019). Egelhofer et al. (2020) found that "journalistic reporting on fake news shifts over time from mainly describing the threat of disinformation online, to a more normalized and broad usage of 
the term in relation to attacks on legacy news media". There is no universally accepted definition of fake news, but as a working definition we assume in this paper that disinformation or fake news means "deliberately presenting false information as news" (Nimmo et al, 2017). Interdisciplinary research on fake news and factors contributing to their development has been conducted with particular intensity since 2016, following the crisis of trust towards information in the context of presidential elections in the USA and France, but also in the context of the Ukrainian conflict (Khaldarova \& Panti, 2016). According Kreft (2019), research on fake news is carried out in the following main fields: reliability of information in the context of high trust towards the Internet as the information environment (Metzger et al., 2009; Morris et al., 2012; Turcotte et al., 2015), social responsibility of the biggest search engines for the dissemination of fake news (Zhang et al., 2013) and research on the creation and dissemination of fake news through media users, bots or "cyborg" accounts, (Gorva, 2017; Allcott \& Gemtzkow, 2017), etc. Since the verification of news is a difficult and time-consuming analytical process, many research activities tend to focus on the identification, tagging and elimination of fake news using algorithms (Ferrara et al., 2016; Lischka, 2017) or looking for broader community solutions to counteract disinformation (Starbird \& Arif, Wilson, 2019; Starbird, 2020).

Scientists test the efficiency of algorithmic technologies to fight fake news on Facebook, Twitter and other portals (Jain et al., 2017; Kumar et al., 2017) and constantly develop new automatic identification systems (Shao et al., 2016; Vosoughi, 2015). Despite these efforts, technological interventions to reduce the spread of disinformation have limited effects. "Going forward, the field aims to identify social factors that sustain a culture of truth and to design interventions that help reward well-sourced news" (Combating Fake News, 2017). The scientists of the Data\&Society group highlight that the information problem we are facing right now "is less one of moderation (of identifying and removing content that is demonstrably false and/or harmful), and more one of mediation (identifying what information is credible, when, and how to communicate these changes)" (Caplan, 2020). Allen et al. (2020) conclude that "future work on misinformation and its potentially corrosive effects on democracy should consider all potential sources of problematic content, as well as the absence of relevant content".

As we can see from the literature analysis, the research on fake news is closely related to the perception of media and trust in the overall media ecosystem.

\section{Trust in media and possibilities to counteract the disinformation}

Traditional mass media organizations (press, radio, television) solve the problem of fake news through sound journalist practice - verifying presented information. However, with digital media, the distribution of news is the prerogative of search engines and social media networks. The latter regard themselves as technological organizations and mostly reject any social obligations that typical media organizations must implement (Kreft \& Hapek, 2019). Over the last few years, platforms like Facebook, Google, and Twitter have been criticized widely for allowing false and harmful information to spread uncontested over their platforms. "When it came to information that could be construed as political, they have been especially reluctant to take a position, handing over responsibility for decisions about truth or falsehood to factchecking organizations" (Caplan, 2020).

Meanwhile, trust in traditional and online media sources is decreasing all over the world, there is no consensus in society about many important issues. Studies show that the mistrust and scepticism of the media impact negatively on mental and physical health in the community, often causing anxiety, stress, anger and the eventual polarisation of society (Thomson et al., 
2018). However, given the low levels of trust in the media and intermediaries involved in digital news consumption, recent studies posit that trust and usage may not be related (Taneja \& Jaeger, 2019). From 2018 to 2019, there was a 22-point increase in "mass population" engagement with the news (Edelman study, 2019). Starbird (2020) gives a comprehensive explanation of this phenomenon: "When information is uncertain and anxiety is high, the natural response for people is to try to 'resolve' that uncertainty and anxiety. ... And so we attempt to come together - either in physical spaces or using communication tools like our phones and now our social media platforms - to 'make sense' of the situation".

Some have found that false news spread faster and farther on the internet than true news, with more profound effects on political (mis)information than on any other type of content (Vosoughi, 2015). The findings of Tsfati et al. (2020) imply the possibility that "most people hear about fake news stories not from fake news websites but through their coverage in mainstream news outlets." Thus far, only a limited attention has been directed to the role of mainstream media in the dissemination of disinformation. The results of a representative survey in the USA show that $64 \%$ of adults say fake news "cause[s] a great deal of confusion about the basic facts" (Barthel et al., 2016). Additionally, 23\% of respondents stated that they have shared a made-up story, with $14 \%$ knowing it was fake.

As we can see, a common awareness of the presence of fake news is not necessarily followed by the equally common verification or elimination of such news. With respect to the possibilities of counteraction, $45 \%$ of the participants stated that government, politicians and elected officials have a responsibility to prevent the spread of fake news, $43 \%$ held the public responsible, with $42 \%$ holding social networking sites and search engines responsible" (Barthel et al., 2016). In Germany, $80 \%$ of participants expect the authorities to take immediate action, and $72 \%$ want to see state IT centres of defence established (Reuter et al., 2019). Most of these studies have relied on quantitative methods but there have been a few exceptions, such as Meier et al. (2018), who studied strategies for audience engagement from the perspective of journalists and other media practitioners. A recent study adopted the cognitive perspective to analyse who is more likely to read, believe and/or share fake news and has found that, on average, consumers are as good at fact-checking as the organizations evaluating the quality of information (Pennycook \& Rand, 2019).

Thus, the involvement of broader social groups in counteracting fake news is an ongoing scientific problem. In response to the resulting challenges and to seize new opportunities, ALLEA (European Federation of Academies of Sciences and Humanities, representing more than 50 academies from over the world) has highlighted as strategic priorities the engagement of intellectuals and academics with the public, "to do more deliberation about important public affairs and stimulate public discourse that is more about reaching an agreement than merely about fake news and polarization" (Trust in Science and Changing Landscapes of Communication, 2019). Scientists, media users, journalists, communication managers and other stakeholders are being encouraged to collaborate in combatting fake news and promoting a culture that values and promotes truth. A similar initiative is Wikitribune, so called "evidencebased journalism", which aims to pair journalists with volunteer community contributors to cover political topics, science and technology. Wikitribune differentiates itself from traditional news organizations by allowing the online community to work with professional reporters to represent facts and offer greater transparency about what goes on in a newsroom (Combating Fake News, 2017). Another initiative is the Center for an Informed Public at the University of Washington, which brings diverse voices from across industry, government, non-profits and other institutions together to confront the problem through research, education, policy and engagement efforts. The centre translates research about misinformation and disinformation 
into policy, technology design and public engagement, using a network of urban and rural libraries, national network of educators, and institutional partners (http://www.cip.uw.edu/).

Resulting from our literature review, the basic research problem is to provide answers to the following questions:

- What are the changes in the perception of fake news and attitudes towards misinformation? How do users experience interaction with fake news and which methods do they use to verify information?

- How can collaboration between stakeholders lead to effective community solutions for combating fake news?

\subsection{Context for combating disinformation in Lithuania}

Online disinformation is considered a major challenge for modern democracies. It is widely understood as misleading content produced to generate profits, pursue political goals, or maliciously deceive. Humprecht et al. (2020) claim that some countries are more resilient to online disinformation than others. Lithuania is an interesting case study for fake news due to its geopolitical situation and its status as a former Soviet state now in the EU. Lithuania was the first Soviet republic to declare the re-establishment of its independence on March 11, 1990. Russian media sometimes refer to this fact, claiming that Lithuania (and the other Baltic States) "destroyed the Soviet Union". The main challenges confronting Lithuania in the field of information security are cyberattacks aiming to destroy information channels and the Kremlin's disinformation and information influence campaigns. A. Kazlauskas, analyst at Debunk.eu, identified two general trends of disinformation targets. First of all, the purposeful aim to undermine public confidence in the authorities - government, health care system, academics and science in general. The second aim of disinformation is to undermine the trust in democratic institutions that maintain peaceful world order, such as NATO and the European Union (Kazlauskas, 2020).

On state level, information security is a high priority. At the same time, cooperation between the different state agencies and institutions in this sphere is quite low. Furthermore, experts point to a number of domestic challenges to Lithuania's information security: unsustainable media landscape, dependence on some groups of interests or business media channels, small media market, insufficient media literacy among Lithuanian society (Denisenko, 2018). Representative research on media literacy and information and patterns of media use in Lithuania (2017) show that media users are not critical of content in social media (Žiniasklaidos priemonių naudojimo raštingumo tyrimas, 2017). Only 15 to $20 \%$ of users pay attention to the dissimilarities in facts presented by different sources, $68 \%$ of users claim they ignore the appearance of fake news in media. On the other hand, Lithuania is a democratic country with a high level of media freedom. In 2020, the World Press Freedom Index placed Lithuania 28th (35th in 2016) out of 180 countries. The first fact-checking initiatives emerged in Lithuania a few years ago. The biggest news portal Delfi.lt created a tool against 'false news' in cooperation with Google (in the framework of the 'Digital News Initiative'). Another initiative, Debunk.eu is a Lithuanian-born initiative which merges all means necessary to counter disinformation: the AI-based analytic tool that spots and identifies disinformation in online articles within 2 minutes from real time, the civil society of 'elves', the journalists who verify claims and the newsrooms that seek maximum outreach. These examples show that the initiative of factchecking organizations in Lithuania is in the hands of journalists. 


\section{Methodology}

Our qualitative research illuminated the practices and interpretations around the perception of fake news, and about citizens' perceptions of countermeasures in Lithuania. We provide an overview of the current situation in Lithuania, offering answers to questions of attitude, interaction, and counteraction with respect to fake news. Our findings are based on 12 semistructured expert interviews conducted from January to April 2020 with the main stakeholders in the media ecosystem. Expert interviews have some significant advantages over other methods of data collection. First of all, this type of survey is uniquely aimed at obtaining reliable data because the respondents' competence is very high (Dorussen et al., 2005). Another advantage lies in the fact that "respondents are highly qualified in the analysed question, it eliminates the need to use additional screening and clarifying questions aimed at revealing true, but hidden from the interviewer respondent views" (Libakova \& Sertakova, 2015). The interviews were conducted face-to face by the authors, and were intended to recruit experts from the following stakeholders' groups: scientists (2), communication managers (3), government representatives (2), journalists (3), business association representatives (2), following the guidelines of "maximum variation sampling" strategy (Lindlof et al., 2002).

The experts on the subject matter were identified according to the following criteria: education, skills, position, relation to the research topic, experience in the communication field, level of public recognition, visibility in Lithuanian media environment, publications in the field of fake news, interest in the disinformation issue. Conversations were recorded using digital voice recorders and then transcribed. The participants verbally agreed to be part of the research project and were not compensated for their collaboration. Pseudonyms are used throughout the paper to protect their privacy. Some interviews were conducted in the Lithuanian language. All participants are Lithuanian citizens. When quotes from these participants are cited in the paper, they appear in English. They have been translated by the authors, who are bilingual. Interviewers asked questions to trigger discussion about each of these topics, and then followed the flow of the conversation (the structured questions and a systemic text condensation related to the interview questions are presented in Appendix A).

We processed the content collected from each of the interviews, identified affinities across participants, and then distilled a collection of ideas and core insights in accordance with the conceptual analysis framework. Several sub steps were involved, starting with the researchers familiarizing themselves with the data (reading \& re-reading), coding the text, defining key themes and providing a coherent narrative using quotes from interviews to explain the relation between the major and minor categories defined during literature review (Table 1) and interview data. Researchers used supporting strategies such as abstraction, deduction, contextualization whilst conducting qualitative analysis, and the interpretative analysis of content and its 'contextual' analysis. Similarities and differences between the identified relations and variables were highlighted, also distinguishing extreme, non-typical cases and linking, integrating cases of content that are closely related. Using an iterative approach with inductive and deductive methods to the hermeneutic circle, we evaluated the findings against the literature and the conceptual framework. Data were analysed in the context of participants' ideas, arguments and opinions in order to deepen the researchers' understanding of the analysed issues. 


\section{Findings}

Our research was structured around the three themes presented in Table 1 below. Each topic was related to the structured interview questions ( 2 or 3 questions on each topic), presented in Appendix A.

\begin{tabular}{|c|c|c|}
\hline Themes & Major categories & Minor categories \\
\hline \multirow{2}{*}{$\begin{array}{l}\text { a) Attitudes towards } \\
\text { Fake news (questions } \\
1 \text { and } 2 \text { ) }\end{array}$} & $\begin{array}{l}\text { Distinctions between fake } \\
\text { news and disinformation }\end{array}$ & $\begin{array}{l}\text { Disinformation, distorted news, false information, } \\
\text { information far from reality }\end{array}$ \\
\hline & $\begin{array}{l}\text { Opinions about the threats } \\
\text { coming from fake news }\end{array}$ & $\begin{array}{l}\text { Threats to individual decision-making, threats to } \\
\text { society, quality of news }\end{array}$ \\
\hline \multirow{3}{*}{$\begin{array}{l}\text { b) Interaction with } \\
\text { fake news (questions } 3 \\
\text { and } 4 \text { ) }\end{array}$} & Flows of disinformation & Becoming more alert regarding fake news \\
\hline & Credibility & $\begin{array}{l}\text { Discovering information bubbles and interest } \\
\text { groups, trustworthiness of news sources, constant } \\
\text { flow of information }\end{array}$ \\
\hline & Trusted sources & $\begin{array}{l}\text { Reputation of media source, reputation of the } \\
\text { author, authority, the sources of funding, references } \\
\text { used for argumentation }\end{array}$ \\
\hline \multirow{3}{*}{$\begin{array}{l}\text { c) Counteraction of } \\
\text { fake news (questions } \\
5,6 \text { and } 7 \text { ) }\end{array}$} & $\begin{array}{l}\text { Collaboration between } \\
\text { stakeholders in the media } \\
\text { ecosystem }\end{array}$ & $\begin{array}{l}\text { Journalists, researchers, politicians, citizens as } \\
\text { media users, communication professionals, teachers } \\
\text { and especially children. }\end{array}$ \\
\hline & Methods of counteraction & $\begin{array}{l}\text { Importance of long-term strategies, development of } \\
\text { media literacy competencies and critical thinking } \\
\text { skills }\end{array}$ \\
\hline & $\begin{array}{l}\text { Preparedness to participate } \\
\text { in the process of managing } \\
\text { disinformation }\end{array}$ & $\begin{array}{l}\text { Willingness to participate in the process of } \\
\text { counteracting disinformation, quality of actions, } \\
\text { citizen engagement. }\end{array}$ \\
\hline
\end{tabular}

Tab. 1. Major and minor categories in semi-structured interviews. Source: Authors.

\section{a) Attitudes towards fake news}

Distinction between fake news and disinformation. According to the respondents, the concept of fake news should be clearly defined in the first place (B). Participants from the group of government representatives questioned the use of the term "fake news": "It should be mentioned that fake news is an obsolete term and should be turned into 'disinformation'. EEAS (European External Action Service) and EU Ministry of Foreign Affairs are in discussions with scientists about the use of the term" (A). In his opinion "disinformation" is a more adequate term, "currently understood as false and incorrect information, is considered in a broader spectrum covering interference in the elections, manipulation with public opinion and the dissemination of misleading information" (A). The interviewees are aware of the emergence of the term fake news more often both during and after the 2016 US presidential election campaign, but they claim that this should not be considered as a new phenomenon, "it is a social (public) phenomenon, common to human communities since the old times" (B). The increasing interest is "caused by the development of fake news in social media, as there are no special tools to identify and neutralize such threats" (B1). The respondents can be divided into two groups with regard to defining the term: most of them agree that it is "distorted news" (D), "false information" $(A, D, E)$, "information far from reality" $(B)$. The second group defines the term by distinguishing fake information and disinformation. "This is the big difference between 
rumours, which are unintentionally disseminated, and fake news, which may arise from the content (while creating the illusion of another meaning of the content)" (C1). Disinformation is defined by its "conscious dissemination with a clear perception that it is fake" $(G)$ or "being spread with a purpose towards impact, then we can call it fake news" (F).

Opinions about the threats coming from fake news. Due to the rapid spread of disinformation, many interviewees had a negative opinion of the quality of the news in recent time. "We should consider disinformation as a serious issue, posing a threat to the economy, health, the organization of elections, emotional well-being and international collaboration" (A). The Dunning-Kruger effect was mentioned in one of the interviews as a possible threat due to fake news: "the less one knows, the more fanatic he/she can become. The more a person is being attacked, the more one resists, a good example could be the $5 G$ network development" (D). Most participants agree that fake news causes serious problems with respect to individual decision-making and society as a whole: it "works as opposition within the society" (F); "fake data leads to fake solutions" (F2); "Information based on lying is similar to the real news" (E); "people think they make their own decisions but it is not true, they make decisions based on the information they have" $(C)$. Indeed, "I believe, that fake news does not create specific threats, as it is just a natural and unavoidable social expression" (B), it is "based on the emotional background of current issues" (E).

\section{b) Interaction with fake news}

Becoming more alert regarding fake news. The interviewees defined the following as having the most common flows of disinformation: Covid-19, vaccination in general, global warming, disinformation originating in Russia and China, conspiracy theories, election campaigns, regional and international crises, etc. All participants had interacted with fake news and noticed the increased amount of disinformation in recent months in the context of the Covid-19 pandemic, covering "virus treatment, origin and spread" (A): "I noticed it everywhere. Even speaking about insignificant things" (D). "There are several areas where fake news might be called a direct lie, for example one may find a scandalous text or information right next to a celebrity photo and this forces you to connect the two" (E); "The scale of disinformation is extremely high" (B).

Discovering information bubbles and interest groups. Many interviewees were concerned about the trustworthiness of news on social media, which is becoming the main source that provides a constant flow of information. Some participants indicated the problem in the "information bubbles" around them: "Social media algorithms are working in a way that I receive a huge amount of news that are relevant for me. The situation became more dangerous when the algorithm started providing me with the news that are important for my friends instead of the whole information flow" $(C)$; "The media news readability is directly connected with the ads, which also requires more news to be created. Furthermore, the content of the news should be created in accordance with popularity" (I); "Usually, people look for news in a state of relaxation, it means they are not very attentive towards the news they receive and more easily accept information which is in alignment with their opinion" $(F)$. One important reason for false information to emerge could be a conflict of interests: "Due to my working environment (fake news in the field of law and justice), I clearly see the reasons and relations among the interested individuals" $(F)$. This leads to the polarization of society into competing interest groups.

Complex examination of different sources by testing the credibility of news. The interviewees mentioned the following aspects while checking the credibility of news: the reputation of a media source $(\mathrm{A}, \mathrm{K})$ or the reputation of the author, authority $(\mathrm{A}, \mathrm{B}, \mathrm{D}, \mathrm{F})$; the 
sources of funding (A); references used for argumentation $(\mathrm{H})$. Summarizing the rationale behind checking news, the following strategy was emphasized: "Fake news spread is caused by trust in one source of data (even if it is an authority). Therefore, the only way to get out of it - complex examination of different sources of data " (C). Some of the respondents mentioned checking scientific databases (E, F) or using specific methodologies ("Speaking of the most effective methodologies, I would mention the RESIST methodology, which is developed by the UK Government" (B); "I always rely on several trusted sources of information and looking for worldwide available information discussing that topic" (E)). Some participants supplemented their answers with specific aspects, such as media literacy (E), empowerment of critical thinking and deconstruction skills ("deepening the competencies on the topics by subscribing to scientific databases, despite the fact that even credible surveys have already been denied or found to be fake" $(F)$ ) and searching for contradicting information, "because you might not find anything at all if you keep searching only for confirmation" (E). Another strategy: "One should pay attention to the content and rethink "who is looking for an advantage? who wants me to believe?" (C1).

\section{c) Counteraction of fake news}

Collaboration between stakeholders in the media ecosystem. A large group of interviewees (A, A1, B , C, D) believe the process of testing news should involve all stakeholders in the media ecosystem (journalists, researchers, politicians, citizens as media users, communication professionals, teachers, etc.): "everyone, starting from developers to consumers, including the intermediaries" (B). However, some participants highlighted the responsibility of governmental authorities (D) or "the fourth estate, the journalists, they should be our guardians" (E), because "the ordinary citizen is not capable of distinguishing the truth" (E), and "not all the citizens have enough skills to do it; however, they can be taught media literacy" $(E)$; "we cannot expect media users to check information by themselves" $(G)$. Some mention that collaboration must be good quality, and that not all stakeholders "have the necessary skills for it" (D). The whole society, especially children, needs education ("I believe in science and education" (F); "teachers are also responsible" (H)). The academic community is already involved in this process according to $\mathrm{C}$, but "it is hard to tell which group of stakeholders should lead the whole process" (C). "Great responsibility goes to the search engines and social media platforms, as well as international organizations, which have to communicate in a timely, persuasive and understandable manner" (A). In addition, the "influence of proactive citizens' organizations" $(G)$ on developing a culture of truth was identified as one of the important factors fostering collaboration between stakeholders.

Methods of counteraction. Trying to identify the possibilities of counteracting disinformation, the interviewees emphasized the importance of long term strategies $(\mathrm{F})$, the development of media literacy competencies and critical thinking skills: "awareness in the society about threats caused by fake news (I); "teaching society members how to recognize fake news" (C); it is "very important to educate children. We also need to educate the society; however, it is very difficult" (D); "critical thinking and society education should be a priority, as well as media literacy" (E); "we have to make a clear distinction between fake news and news which we don't like, politicians often use this feature to win their voters" $(C)$. One of the methods of developing critical thinking could be "to read news on CNN and Fox News, and to observe how news influences you, which position you take after reading information" (B). One participant claimed, that it is "very important to identify false fact in an early stage because it is too late to interfere when the society has already been polarized" (B). The interviewees distinguish the process of verification of fake news from tagging and elimination: "verification is possible 
through algorithms, but more important is the disruption of information spread: it is particularly difficult to stop the spread of information that is fake on social media if the message becomes viral" $(C)$. RESIST methodology, which is developed by the UK Government (B), and the inclusion of social media administrators could be very helpful by supporting the next steps after the identification of fake news - tagging and elimination. "Wikipedia is working really well, as the content is stored only after the process of verification is performed. The U.S. Congress will force Google, Facebook to do the same" (C).

Discussing the usage of information and communication technologies (ICT) in the process of counteraction, some participants believe that "it is beneficial, still, difficult to be implemented: it would be great if Facebook had a "let's apply critical thinking" button, but this is not realistic" $(C)$. "The problem lies in the technological solutions of social media platforms. They ignored the problem of fake news until recently" (D). Another opinion: "I do not trust information technology " (E).

Preparedness to participate in the process of managing disinformation. The majority of interviewees were willing to participate in the process of counteracting disinformation if "they have the necessary competencies" (A), "clear tasks are defined" (C); "I would like to contribute - knowledge is like a "currency"(E); "the scale of misinformation is so huge that I have no idea how to implement the counteraction" (D). Some interviewees informed that they are already involved in the verification of news as an activity related to their profession (A, B): "I have contributed to the Lithuanian initiative "Demaskuok" through the magazines Politico, The Economist and other international organizations" $(A)$. Aspect that were mentioned more than twice: "the quality of actions is important" (G); "to cause no harm - this requires competencies. I agree with the Hippocratic principle: do no harm, do no damage through ignorance and inexperience" $(F)$. Interviewees questioned whether or not citizens' involvement in managing disinformation is an effective tool: "Currently, more and more scientists keep saying that the verification and elimination of news is necessary, but not the most effective way to combat disinformation; however, the dissemination and verification of facts is necessary" (A). Indeed, "the society is not yet ready for collaboration because fake news is not acknowledged as a real threat. Society is still quite naive regarding this issue - this is not a priority problem at the state level either" (D); "we are still not afraid of this phenomenon (fake news) and we do believe that it is somewhere far away from us" (F).

\section{Discussion and conclusions}

The paper aimed to shed light on three perspectives related to fake news: on the perception of fake news; perceived interaction and opinion on counteraction while targeting various stakeholder groups. By reflecting on the findings of the qualitative research in Lithuania we assert that the concept of fake news is not yet clearly defined, the use of the term being under continuing discussion by scientists, UNICEF and EU authorities. The discussed terms are "disinformation" or "fake news", information that is false and deliberately created to harm a person, social group, organization or country, and "misinformation", defined as information that is false but not created with the intention of causing harm. Based on our literature review we recommend the use of the term "disinformation" rather than "fake news" in ICT literature.

Due to the rapid spread of disinformation, many interviewees had a negative opinion of the quality of news in recent times. However, given the low levels of trust in media and the several intermediaries involved in digital news consumption, recent studies posit that trust and usage may not be related. Social media channels and search engines remain the primary news and information sources. It can be concluded that media users are aware of the threats caused by 
disinformation. Participants agree that fake news present serious threats in terms of individual decision-making and society as a whole. The interviewees defined the following as the most common disinformation flows: Covid-19, vaccination in general, global warming, disinformation coming from Russia and China, conspiracy theories, election campaigns, regional and international crises, etc. All participants interacted with fake news and noticed the increased amount of disinformation in recent months in the context of the Covid-19 pandemic, covering virus treatment, origin and spread. In addition, the research participants identified information "bubbles", hidden commercial advertisements, and polarization brought about by the conflict of interests as the biggest problems in today's media ecosystem.

Our research indicates that the current state of the media landscape forced users to search for opinion leaders who can offer credibility assessments. It can be concluded that the danger of creating personalized "information bubbles" emerges with this tendency. The interviewees identified the following aspects while checking the credibility of news: the reputation of media source, author or authority, the sources of funding, references used for argumentation. Indeed, media users build personalized information systems around themselves, tending to rely on personal contacts through social media. The spread of fake news is caused by trust in a single source of data, thus a complex examination of different sources was emphasized as the most rational working strategy to identify disinformation. Supporting activities could be checking scientific databases, searching for contradicting information or using specific methodologies, such as RESIST. The results indicate that interaction perspectives are similar to assessment results in other EU countries - Poland (Kreft \& Hapek, 2019), Germany (Reuter et al, 2019) and Switzerland (Schafer et al, 2018). They also demonstrate that media users gradually take over journalists' practices for checking facts (Wagner et al, 2019).

The innovative character of the research is due to the focus on the underexplored social factors of collaboration between media users, media organizations, scientists, communication managers, journalists and other important actors in the media ecosystem. Many participants agree that the process of testing news should involve all stakeholders in the media ecosystem (journalists, researchers, politicians, citizens as media users, communication professionals, teachers, etc.). The academic community was mentioned as a good example of counteraction, being actively involved as it is in science communication in response to disinformation. However, government authorities, social media platforms and journalists are identified as having the main responsibility for the verification, tagging and elimination of disinformation. Society still relies on the belief that journalists are responsible for telling the truth, as was the case in traditional media.

In attempting to identify the possibilities of counteracting disinformation, the interviewees emphasized the importance of long-term strategies. The main preconditions of fostering a culture of truth include media literacy which needs to be introduced from an early age, empowerment of critical thinking, and deconstruction skills. Regarding collaboration between stakeholders, interviewees expressed their preparedness to participate in the process of counteracting disinformation, although they describe collaboration as very difficult and timeconsuming because it demands an increased awareness of society, inspired leadership, clearly defined tasks and stakeholder competencies. Currently, not all media users are prepared and/or have the necessary competencies to combat fake news, therefore citizen engagement might actually negatively influence the quality of the counteraction process. Indeed, proactive citizens' organizations and NGOs could be an important catalyst fostering collaboration between stakeholders. It can be concluded that society members are aware that the application of ICT and algorithms is necessary, though not a sufficient tool in the fight with fake news. The responsibility of governments could be to create the structures, methodologies and supporting 
educational activities to involve the stakeholders in collaborating activities combating disinformation.

The study has several limitations. It was conducted in the Lithuanian capital city in which practices of news consumption can be different from other places and countries. The research was conducted as an exploratory study with a small number of participants and should be expanded into other stakeholder groups and places, and also supported be representative survey results. Future research may also test for correlations between the three analysed topics to gain a deeper insight into the causal relationships between general attitudes, perceived interaction and opinions on counteraction while targeting various groups defined by demographic factors.

Finally, we identified areas where additional research is needed in order to provide a better understanding of the fake news phenomenon and ways of mitigating it. Further research is needed on targeted attitudinal or behavioural change, perception differences, ideological motives, the influence of age, education and income on attitudes and interaction, and many other variables. The results show that future research should involve methodologies for critical, responsible news sharing and the deconstruction of false news. Our findings concerning Lithuania's media ecosystem may not only be useful with respect to this single case, but also contribute to an understanding of the counteraction of fake news in other European countries with similar media-cultural conditions. These findings may contribute to the development of practical policies as the success of ICT governance strongly depends on the willingness of all actors in the media ecosystem.

\section{ORCID}

Aelita Skarzauskiene (D) http://orcid.org/0000-0003-1606-0676

Monika Maciuliene (D) http://orcid.org/0000-0002-8527-7468 


\section{Appendix A}

\section{Questions for semi-structured interviews}

1. What is your opinion regarding the threats coming from the fake news?

\section{Systemic text condensation}

"consider disinformation as a serious issue", "threats towards economy, health, elections, emotional well-being, international collaboration", "no special tools to identify and neutralize such threats", "might cause serious destruction in order to achieve political goals", "segregation of opinions, influence om the scale of values", "cultural and political sustainability is under threat", "works as opposition is a huge threat". "the Dunning-Krueger effect is working: the less one knows, the more fanatic he or she can become",

"knowledge is a currency in the century of information, therefore fake news cause serious problems", "fake data leads to fake solutions", "Information based on lying is similar to the real news" ,"people think they make their own decisions but it is not true, they make decisions based on the information they have", "with the help of technology it is spreading really fast", "created by artificial intelligence", "algorithms started providing me with the news that are important for my friends instead of the whole information flow", "people don't know what is true or fake. People even form separate groups with a common belief in fake news and are distanced from society".

2. How would you describe fake news?

"the whole concept is not clear itself", "fake news should not be taken into consideration as a new phenomenon", "it is just a natural and

unavoidable social expression", "a social (public) phenomenon, common to human communities since the old times", "fake news is an obsolete term and should be turned into 'disinformation'. EEAS (European External Action Service) and EU Ministry of Foreign Affairs are in discussions with scientists about the use of the term", "currently understood as false and incorrect information", "considered in a broader spectrum covering interference in the elections, manipulation with public opinion and dissemination of misleading information", "distorted news", "false information", "information far from reality", "big difference between rumors, which are unintentionally disseminated, and fake news, which may arise from the content", "conscious dissemination with a clear perception that it is fake", "being spread with a purpose towards impact, then we can call it fake news", "the same objectives that are taken into account in a different perspective create different realities".

3. Have you noticed disinformation and, if so, in which areas and through which sources?
"I have noticed it everywhere. Even speaking about insignificant things", "political news, elections, climate change - everywhere where a conflict of interests occurs", "several areas where fake news might be called a direct lie, for example one may find a scandalous text or information right next to a celebrity photo and this forces you to connect the two", "The scale of disinformation is extremely high", "huge amount of misinformation concerning Covid-19 is circulating around, covering the treatment, origin and political climate of it", "disinformation from Russia and China", "interference regarding the political process in Western democracy", "dissemination of conspiracy theories", "global warming", "the movement of "anti-Mexicans", "media news readability is directly connected with the ads, and demand for ads requires more news to be created. What is more, even more dangerous, is that the content of the news has to be created in accordance with popularity", "I am more anxious about selective truth, such as vaccination, the spread of fake news just for the reason of formulating the opinion, form a group, which later turns into an active group on its own", "due to my working environment (fake news in the 


\begin{tabular}{|c|c|}
\hline & $\begin{array}{l}\text { field of law and justice) I clearly see the reasons and relations among } \\
\text { the interested individuals. This happens more than once a month". }\end{array}$ \\
\hline $\begin{array}{l}\text { 4. Please, identify the trusted } \\
\text { sources while searching for } \\
\text { information. Do you have } \\
\text { experience in identifying, } \\
\text { tagging or eliminating fake } \\
\text { news? If so, could you please } \\
\text { share your experience? }\end{array}$ & $\begin{array}{l}\text { "Fake news spread is caused by trust in one source of data (even if it is } \\
\text { an authority). Therefore, the only way to get out of it - complex } \\
\text { examination of different sources of data", "speaking about the most } \\
\text { effective methodologies, I would mention the RESIST methodology, } \\
\text { which is developed by the UK Government", "I always rely on several } \\
\text { trusted sources of information and looking for worldwide available } \\
\text { information discussing that topic", "deepening the competencies on } \\
\text { the topics by subscribing to scientific databases, despite the fact that } \\
\text { even credible surveys have already been denied or found to be fake", } \\
\text { "because you might not find anything at all if you keep searching only } \\
\text { for confirmation", "one should pay attention to the content and rethink } \\
\text { "who is looking for advantage? who wants me to believe?"”, "I trust } \\
\text { those who manage to avoid the same mistakes (while the random } \\
\text { mistakes are unavoidable)",I compare published information with } \\
\text { similar information in other channels with a high level of trust", } \\
\text { "critical thinking is the most important factor", "the fourth estate, the } \\
\text { journalists, they should be our guardians, as the ordinary citizens are } \\
\text { not capable of distinguishing the truth", "I pay attention to the credible } \\
\text { individuals such as the pope or foreign politicians. I also double check } \\
\text { if there are additional sources writing about them", "I always rely on } \\
\text { several sources of information and looking for foreign information } \\
\text { discussing that topic. I also believe it is worth to look for the opposite } \\
\text { information, just because you might not find anything at all if you } \\
\text { keep searching only for confirmation", "You can stuck with just one } \\
\text { point of view, while the theme is unambiguous", "one should make } \\
\text { efforts, while deepening the competencies on the topics based on } \\
\text { scientific data (despite the fact that even credible surveys have already } \\
\text { been denied or found to be fake)", "I also rely on the sources that I } \\
\text { have been using for a long time. I also set the boundaries for myself", } \\
\text { "I try to select the individuals with no trust issues". }\end{array}$ \\
\hline $\begin{array}{l}\text { 5. Please identify the social } \\
\text { groups that should be involved } \\
\text { in the news verification process } \\
\text { (journalists, researchers, } \\
\text { politicians, citizens, public } \\
\text { relations professionals, etc.). } \\
\text { Who has to take responsibility } \\
\text { for counteracting fake news? }\end{array}$ & $\begin{array}{l}\text { "everyone, starting from developers to consumers, including the } \\
\text { intermediaries", "everyone having an authority: journalists (quite } \\
\text { inactive right now), as well as scientists, politicians", "the fourth } \\
\text { estate, the journalists, they should be our guardians", "the ordinary } \\
\text { citizen is not capable of distinguishing the truth", "not all the citizens } \\
\text { have enough skills to do it; however, they can be taught media } \\
\text { literacy", "we cannot expect media users to check info", "I believe in } \\
\text { science and education", "teachers are also responsible", "it is hard to } \\
\text { tell which group of stakeholders should lead the whole process", } \\
\text { "great responsibility goes to the search engines and social media } \\
\text { platforms, as well as international organizations, which have to } \\
\text { communicate in a timely, persuasive and understandable manner", } \\
\text { "the influence of proactive citizens' organizations", "a huge } \\
\text { responsibility lies with the teachers, as they strengthen children's } \\
\text { digital literacy ant text comprehension", "the function of news } \\
\text { verification should be performed by all the stakeholders in the process } \\
\text { (from developers to users, including all the intermediaries), because it } \\
\text { is part of the knowledge dissemination process", "nowadays Google is } \\
\text { working hard on projects with global media channels to create } \\
\text { platforms for denouncement", "it is hard to believe that someone is } \\
\text { going to check the channels. Wikipedia is working really well on it. } \\
\text { The U.S. Congress will force Google, FB, to do the same", }\end{array}$ \\
\hline $\begin{array}{l}\text { 6. What, in your opinion, are the } \\
\text { most useful methods of } \\
\text { counteracting fake news? }\end{array}$ & $\begin{array}{l}\text { "awareness in the society of the threats caused by fake news", } \\
\text { "teaching society members how to recognize fake news", "very } \\
\text { important to educate children. We also need to educate the society; } \\
\text { however, it is very difficult", "critical thinking and society education }\end{array}$ \\
\hline
\end{tabular}




\begin{tabular}{|c|c|}
\hline & $\begin{array}{l}\text { should be a priority, as well as media literacy", "we have to make a } \\
\text { clear distinction between fake news, and news which we don't like, } \\
\text { politicians often use this feature to win their voters", "to read news on } \\
\text { CNN and Fox News, and to observe how news influences you, which } \\
\text { position you take after reading information", "very important to } \\
\text { identify false fact at an early stage, because it is too late to interfere } \\
\text { when the society has already been polarized", "the verification is } \\
\text { possible through algorithms, but more important is the disruption of } \\
\text { information spread: it is particularly difficult to stop the spread of } \\
\text { information that is fake on social media if the message becomes viral", } \\
\text { "I would focus on long-term strategies so the society would be able to } \\
\text { make critical choices", "currently everything is working } \\
\text { unsystematically". }\end{array}$ \\
\hline $\begin{array}{l}\text { 7. How important is the problem } \\
\text { of disinformation for you? } \\
\text { Would you be able or wish to } \\
\text { collaborate in the activities } \\
\text { related to identification, tagging } \\
\text { and elimination of fake news? }\end{array}$ & $\begin{array}{l}\text { "I do have } 2 \text { years' experience while working in the field of } \\
\text { disinformation and deconstruction", "I am actively working on these } \\
\text { issues in my career life", "if I have the necessary competencies", } \\
\text { "clear tasks have to be defined", "I would like to contribute - } \\
\text { knowledge is like a "currency"," "the scale of misinformation is so } \\
\text { huge that I have no idea how to implement the counteraction", "I have } \\
\text { contributed to the Lithuanian initiative 'Demaskuok' through the } \\
\text { magazines Politico, The Economist and other international } \\
\text { organizations", "the quality of actions is important", "to cause no } \\
\text { harm - this requires competencies. I agree with the Hippocratic } \\
\text { principle: do no harm, do no damage through ignorance and } \\
\text { inexperience", "the society is not yet ready for collaboration because } \\
\text { fake news is not acknowledged as a real threat. Society is still quite } \\
\text { naive regarding this issue - this is not a priority problem at the state } \\
\text { level either", "we are still not afraid of this phenomenon (fake news) } \\
\text { and we do believe that it is somewhere far away from us", "as a } \\
\text { citizen I am still working on it and express my opinion","I am happy } \\
\text { with the State Security Department's activities, as it is active in this } \\
\text { field", "this question is very important to me because fake news turn } \\
\text { our world into an illusion", "this issue is very important, especially for } \\
\text { those working in the communication field. This field will be } \\
\text { particularly important in the future", "Contribute? Well, rather yes } \\
\text { than no, but I should be aware about the engagement profile and } \\
\text { competencies in need. It is really important to cause no harm". }\end{array}$ \\
\hline
\end{tabular}

\section{References}

Allen, J., Howland, B, Mobius, M., \& Rotdshild, D. (2020). Evaluating the fake news problem at the scale of the information ecosystem. Science Advanced, 6(14), eaay3539. https://doi.org/10.1126/sciadv.aay3539

Allcott, H., \& Gentzkow, M. (2017). Social media and fake news in the 2016 election (No. w23089). National Bureau of Economic Research.

Barthel, M., Mitchell, A., \& Holcomb, J. (2016). Many Americans Believe Fake News Is Sowing Confusion. http://www.journalism.org/2016/12/15/many-americans-believe-fake-news-issowing-confusion/

Caplan, R. (2020). COVID-19 misinformation is a crisis of content mediation. https://www.brookings.edu/techstream/covid-19-misinformation-is-a-crisis-of-content-mediation/

Combating Fake News. (2017). Harvard University, Combating Fake News: An Agenda for Research and Action. https://www.hks.harvard.edu/publications/combating-fake-news-agenda-research-and-action

Cunha E., Magno G., Caetano J., Teixeira D., \& Almeida V. (2018) Fake News as We Feel It: Perception and Conceptualization of the Term "Fake News" in the Media. In Staab S., Koltsova O., Ignatov D. (eds) Social Informatics, Soclnfo 2018 (pp. 151-166). Springer. https://doi.org/10.1007/978-3-030-01129-1 10

Collins Dictionary Word of the year. (2017). Collins 2017 Word of the Year Shortlist. https://www.collinsdictionary.com/word-lovers-blog/new/collins-2017-word-of-the-yearshortlist,396,HCB.html 
Denisenko, V. (2018). Lithuania: Disinformation Resilience Index. http://prismua.org/en/9065-2/

Dorussen, H., Lenz, H., \& Blavoukos, S. (2005). Assessing the Reliability and Validity of Expert Interviews. European Union Politics, 6(3), 315-337. https://doi.org/10.1177/1465116505054835

Edelman study. (2019). Edelman study: High Levels of Trust in Traditional Media Persist. https://www.newsmediaalliance.org/edelman-study-media-trust/

Egelhofer, J. L., Aaldering, L., Eberl, J., Galyga, S., \& Lecheler,S. (2020). From Novelty to Normalization? How Journalists Use the Term "Fake News" in their Reporting. Journalism Studies, 21(10), 1323-1343. https://doi.org/10.1080/1461670X.2020.1745667

Ferrara, E., Varol, O., Davis, C., Menczer, F., \& Flammini, A. (2016). The rise of social bots. Communications of the ACM, 59(7), 96-104. https://doi.org/10.1145/2818717

Garrett, L. (2020). COVID-19: the medium is the message. The Lancet, 395(10228), 942-943. https://doi.org/10.1016/S0140-6736(20)30600-0

Gorwa, R. (2017). Computational Propaganda in Poland: False Amplifiers and the Digital Public Sphere. Computational Propaganda Project Working Paper Series.

Humprecht, E., Esser, F., \& Van Aelst, P. (2020). Resilience to online disinformation: A framework for crossnational comparative research. International Journal of Press/Politics, 25(3), 493-516. https://doi.org/10.1177/1940161219900126

Edelman study. (2019). Edelman study: High Levels of Trust in Traditional Media Persist https://www.newsmediaalliance.org/edelman-study-media-trust/

Jain, S., Sharma, V., \& Kaushal, R. (2016). Towards automated real-time detection of misinformation on Twitter. In 2016 International Conference on Advances in Computing, Communications and Informatics (ICACCI) (pp. 2015-2020). IEEE.

Kazlauskas, A. (2020) Dezinformacijos apie koronvirusa netrūksta. https://www.vz.It/rinkodara/komunikacija/2020/04/02/demaskuoklt-dezinformacijos-apie-koronavirusanetruksta

Khaldarova, I., \& Pantti, M. (2016). Fake news. Journalism Practice, 10(7), 891-901. https://doi.org/10.1080/17512786.2016.1163237

Kreft J., \& Hapek, M. (2019). Fake news: possibility of identification in post-truth media ecology system. Zarządzanie Mediami, 7(3),133-142. http://doi.org/10.4467/23540214ZM.19.009.11120

Kumar, S., Villa, R. A., \& Carley, K. M. (2017). Identifying Bots that Spread Fake News. SBP-BRiMS. Washington, DC.

Libakoba, N. M., \& Sertakova, A. (2015). The Method of Expert Interview as an Effective Research Procedure of Studying the Indigenous Peoples of the North. Journal of Siberian Federal University. Humanities \& Social Sciences, 1(8), 114-129.

Lindlof, T. R., \& Bryan C. T. (2002). Qualitative Communication Research Methods. Sage.

Lischka, J. A. (2017). A Badge of Honor? How The New York Times discredits President Trump's fake news accusations. Journalism Studies, 20(2), 287-304. https://doi.org/10.1080/1461670X.2017.1375385

Meier, K., Kraus, D. \& Michaeler, E. (2018). Audience Engagement in a Post-Truth Age: What It Means and How to Learn the Activities Connected with It. Digital Journalism, 6(8), 1052-1063. https://doi.org/10.1080/21670811.2018.1498295

Metzger, M. J. (2009). The study of media effects in the era of Internet communication. In R. L. Nabi and M. B. Oliver (eds.), The Sage Handbook of Media Processes and Effects (pp. 561-576). Sage.

Morris, M. R., Counts, S., Roseway, A., Hoff, A., \& Schwarz, J. (2012). Tweeting is believing? Understanding microblog credibility perceptions. In Proceedings of the ACM 2012 conference on Computer Supported Cooperative, Work (CSCW2012) (pp. 441-450). ACM. https://doi.org/10.1145/2145204.2145274

Nimmo, B., Czuperski, M., \& Brookie, G. (2017). BotSpot: the intimidators. Twitter bots unleashed. Social media disruption tactic. https://medium.com/dfrlab/botspot-the-intimidators-135244bfe46b

Jourova, V. (2020). From pandemic to infodemic. https://ec.europa.eu/commission/presscorner/detail/en/speech 201000

Pennycook, G., \& Rand, D. G. (2019). Fighting Misinformation on Social Media Using Crowdsourced Judgments of News Source Quality. Proceedings of the National Academy of Sciences, 116(7), 2521-2526. https://doi.org/10.1073/pnas.1806781116 
Schäfer, M.S., Fuchslin, T., Metag, J., Kirstianse, S., \& Rauchfleisch, A. (2018). The different audiences of science communication: A segmentation analysis of the Swiss population's perceptions of science and their information and media use patterns. Public understanding of science, 27(7), 836-856.

https://doi.org/10.1177/0963662517752886

Shao, C., Ciampaglia, G. L., Flammini, A., \& Menczer, F. (2016). Hoaxy: A platform for tracking online misinformation. In Proceedings of the 25th International Conference Companion on World Wide Web (pp. 745-750). https://doi.org/10.1145/2872518.2890098

Starbird, K., Arif, A, \& Wilson, T. (2019). Disinformation as Collaborative Work: Surfacing the Participatory Nature of Strategic Information Operations. In Proceedings of the ACM on Human-Computer Interaction (No. 127). ACM. https://doi.org/10.1145/3359229

Starbird, K. (2020). How a Crisis Researcher Makes Sense of Covid-19 Misinformation. https://onezero.medium.com/reflecting-on-the-covid-19-infodemic-as-a-crisis-informatics-researcherce0656fa4d0

Tandoc, Jr., E. C. (2019). Tell Me Who Your Sources Are: Perceptions of News Credibility on Social Media. Journalism Practice, 13(2), 178-190. https://doi.org/10.1080/17512786.2017.1423237

Taneja H., \& Jaeger K. (2019). Do People Consume the News they Trust? Incidental News Usage and the HighChoice Media Environment. In Proceedings of the 2019 CHI Conference on Human Factors in Computing systems, paper No. 540 (pp. 1-10). ACM. https://doi.org/10.1145/3290605.3300770

Thomson, R., Garfin, D. R., \& Holman, A. (2018). Distress, Worry, and Functioning Following a Global Health Crisis: A National Study of Americans' Responses to Ebola. Clinical Psychology Science, 5(3), 513-521. https://doi.org/10.1177/2167702617692030

Trust in Science and Changing Landscapes of Communication. (2019). Trust in Science and Changing Landscapes of Communication. https://allea.org/portfolio-item/trust-in-science-and-changing-landscapes-ofcommunication/

Tsfati, Y., Boomgaarden, H. G., Strömbäck, J., Vliegenthart, R., Damstra, A. \& Lindgren, E. (2020). Causes and consequences of mainstream media dissemination of fake news: literature review and synthesis. Annals of the International Communication Association, 44(21), 157-173. https://doi.org/10.1080/23808985.2020.1759443

Turcotte, J., York, C., Irving, J., Scholl, R. M., \& Pingree, R. J. (2015). News recommendations from social media opinion leaders: Effects on media trust and information seeking. Journal of Computer-Mediated Communication, 20(5), 520-535. https://doi.org/10.1111/jcc4.12127

Vosoughi, S. (2015). Automatic detection and verification of rumours on Twitter. Doctoral dissertation. Massachusetts Institute of Technology.

Wagner, M. C., \& Boczkowski, J., M. (2019). The Reception of Fake News: The Interpretations and Practices That Shape the Consumption of Perceived Misinformation. Digital journalism, 7(7), 870-885. https://doi.org/10.1080/21670811.2019.1653208

Žiniasklaidos priemoniu naudojimo raštingumo tyrimas. (2017). Žiniasklaidos priemoniu naudojimo raštingumo lygio nustatymo tyrimas. http://lrkm.Irv.lt/uploads//rkm/documents/files/Ziniasklaidos vartojimas12 galutine.pdf

Zhang, J., Carpenter, D., \& Ko, M. (2013). Online astroturfing: A theoretical perspective. In Proceedings of the Nineteenth Americas Conference on Information Systems (pp. 1-7). AISNET. https://aisel.aisnet.org/cgi/viewcontent.cgi?article=1620\&context=amcis2013

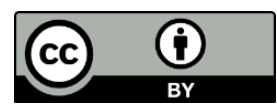

Copyright $(2020$ by the author(s). Licensee Prague University of Economics and Business, Czech Republic. This article is an open access article distributed under the terms and conditions of the Creative Commons Attribution License (CC BY), which permits use, distribution and reproduction in any medium, provided the original publication is properly cited, see http://creativecommons.org/licenses/by/4.0/. No use, distribution or reproduction is permitted which does not comply with these terms.

The article has been reviewed.

Editorial record: First submission received on 1 July 2020. Revisions received on 24 July 2020 and 12 August 2020. Accepted for publication on 14 August 2020. The editor in charge coordinating the review of this manuscript and approving it for publication was Zdenek Smutny (iD. 
